\title{
Compensation Strategy to Eliminate the Effect of Current Measurement Offsets in Grid-Connected Inverters
}

\author{
Chang-Hee Lee ${ }^{*}$ and Jong-Woo Choi ${ }^{\dagger}$ \\ ${ }^{*}$ Department of Electrical Eng., Kyungpook National University, Daegu, Korea
}

\begin{abstract}
For the digital control of systems such as grid-connected inverters, measuring inverter output currents accurately is essential. However, current measurement offsets are inevitably generated by current measurement paths and cause DC current components in real inverter output currents. Real inverter output currents with DC components cause the DC-link capacitor voltage to oscillate at the frequency of a utility voltage. For these reasons, current measurement offsets deteriorate the overall system performance. A compensation strategy to eliminate the effect of current measurement offsets in grid-connected inverters is proposed in this study. The validity of the proposed compensation strategy is verified through simulations and experiments. Results show that the proposed compensation strategy improves the performance of grid-connected inverters.
\end{abstract}

Key words: Current control, Current offset, DC component, DC current injection, Grid-connected inverter, Power quality

\section{INTRODUCTION}

Environmental pollution and limited fossil fuel have prompted research into distributed generation systems using renewable energy sources (i.e., solar cells, fuel cells, or wind turbines) [1]-[4]. Power quality problems have also increased the demand for custom power devices [5]-[7]. These systems are usually operated by grid-connected inverters similar to those shown in Fig. 1. In grid-connected inverters, the precise control of inverter output currents must be achieved because electricity supply companies require adequate certification for harmonic distortion, power factor, and DC components for inverter output currents [8-10]. Accordingly, many methods for the current control of grid-connected inverters have been developed. These methods include the use of the stationary and synchronous frame proportional-integral (PI) regulator [11], [12], stationary frame proportional-resonant (PR) regulator [13]-[15], repetitive-based regulator [16], deadbeat regulator [17], and hysteresis regulator [18].

However, the abovementioned studies do not consider current measurement offsets generated by the current measurement path. Generally, the procedure of current

Manuscript received May 21, 2013; accepted Dec. 24, 2013 Recommended for publication by Associate Editor Kyo-Beum Lee.

†'Corresponding Author: jwchoi@ee.knu.ac.kr

Tel: +82-53-950-5515, Kyungpook National University

*Dept. of Electrical Eng., Kyungpook National University, Korea
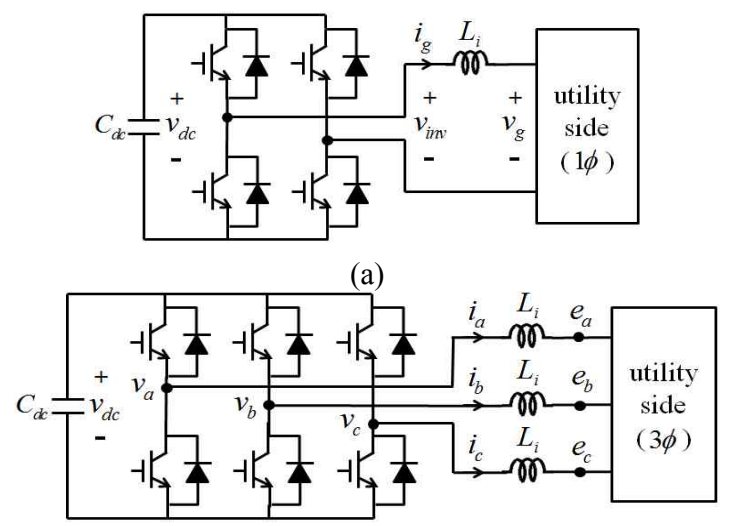

(b)

Fig. 1. Grid-connected inverters. (a) Single-phase grid-connected inverter. (b) Three-phase grid-connected inverter.

measurement is as follows. Inverter output currents are transduced to voltage signals by current sensors and transformed into digital values via low-pass filters and analog-to-digital (A/D) converters. Through this current measurement path, current measurement offsets are inevitably generated and cause DC current components in real inverter output currents. Real inverter output currents with DC current components cause the DC-link capacitor voltage to oscillate at the frequency of the utility voltage. This ripple distorts inverter output current references and 
deteriorates the overall system performance. This approach is called a first-order ripple component in this study.

Calculating current offsets by reading the $\mathrm{A} / \mathrm{D}$ converter repeatedly without current flowing is common practice. However, the effect of the thermal drift of analog devices and switching interference in actual operating conditions makes current offsets vary.

The distortion in inverter output current references caused by the first-order ripple component can be prevented with a notch filter whose center frequency is equal to the frequency of utility voltages. However, the DC components of real inverter output currents injected into the utility side are not eliminated. The problem in DC current injection can be simply solved with a utility frequency transformer. However, this transformer increases the cost and size and reduces system efficiency. Bhat and Dewan [19] proposed a solution based on a high-frequency transformer to decrease the size. However, this solution does not prevent the DC current components of currents injected into the utility side. For these reasons, different solutions have been proposed to remove DC current components [20]-[22], but these solutions require additional elements or sensors.

The solution proposed in this study does not require additional elements and sensors, except for sensors that are necessary to control grid-connected inverters. The proposed solution is thus very cheap and easy to implement. It is also applicable regardless of the topology of grid-connected inverters.

In this study, we analyze how current measurement offsets cause DC current components in real inverter output currents and the first-order ripple component in the DC-link capacitor voltage. A compensation strategy is proposed to eliminate DC current components in real inverter output currents and obtain precise current control.

The remainder of this paper is organized as follows. The effect of current measurement offsets is described in Section II. The proposed compensation strategy is introduced and discussed in Section III. The validity of the proposed strategy is verified by simulations and experiments in Sections IV and V. Finally, the conclusions are presented in Section VI.

\section{EFFECT OF CURRENT MEASUREMENT OFFSETS}

\section{A. Single-phase Grid-connected Inverters}

Fig. 2 presents the block diagram of the current control in consideration of the measurement offsets of the utility voltage and output current in single-phase grid-connected inverters. In Fig. 2, $\delta v_{g}$ and $\delta i_{g}$ denote the measurement offsets in the utility voltage and the inverter output current, respectively, whereas $v_{g_{-} m}$ and $i_{g_{-} m}$ denote the measured utility voltage and inverter output current, respectively. On the assumption that the utility voltage is a complete sinusoidal wave as expressed

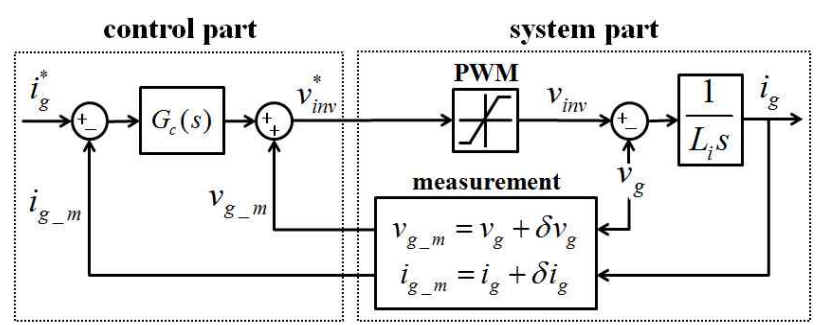

Fig. 2. Block diagram of the current control in consideration of the measurement offsets in single-phase grid-connected inverters.

in Equation (1), the inverter output current reference is expressed as Equation (2) so that active and reactive power may be regulated at the utility side, the pulse width modulation (PWM) is ideal, and the measurement offsets are constant. The inverter output current at the steady state in the current control using a proportional-integral-resonant (PIR) regulator (as expressed in Equation (3)) is expressed in Equation (4).

$$
\begin{gathered}
v_{g}=V_{g} \sin \omega t \\
i_{g}^{*}=I_{d}^{e^{*}} \sin \omega t+I_{q}^{e^{*}} \cos \omega t \\
G_{c}(s)=K_{p c}+\frac{K_{i c}}{s}+\frac{K_{r c} s}{s^{2}+\omega_{0}^{2}} \\
i_{g}=I_{d}^{e^{*}} \sin \omega t+I_{q}^{e^{*}} \cos \omega t-\delta i_{g}
\end{gathered}
$$

As Equation (4) shows, the current measurement offset causes the DC current component injected into the utility side in single-phase grid-connected inverters. At the steady state, using Equations (1) and (4) yields the inverter output voltage as follows:

$$
\begin{aligned}
v_{i n v} & =L_{i} \frac{d i_{g}}{d t}+v_{g} \\
& =\omega L_{i} I_{d}^{e^{*}} \cos \omega t-\omega L_{i} I_{q}^{e^{*}} \sin \omega t+V_{g} \sin \omega t
\end{aligned}
$$

If no power loss occurs in the inverter, the power supplied from the DC-link to the inverter is similar to the inverter output power and can be expressed as Equation (6).

$$
\begin{aligned}
& p_{\text {out }}=v_{\text {inv }} i_{g}=p_{\text {out_d }}+p_{\text {out_ } 1 r}+p_{\text {out_ } 2 r} \\
& p_{\text {out_d } d c}=\frac{V_{g} I_{d}^{e^{*}}}{2} \\
& p_{\text {out_ } 1 r}=-P_{S}\left\{\delta i_{g} \sin \left(\omega t+\phi_{S}\right)\right\} \\
& p_{\text {out_2 } 2 r}=-P_{S}\left\{\frac{I_{d}^{e^{*}}}{2} \cos \left(2 \omega t+\phi_{S}\right)-\frac{I_{q}^{e^{*}}}{2} \sin \left(2 \omega t+\phi_{S}\right)\right\}
\end{aligned}
$$

where

$$
P_{S}=\sqrt{\left(V_{g}-\omega L_{i} I_{q}^{e^{*}}\right)^{2}+\left(\omega L_{i} I_{d}^{e^{*}}\right)^{2}}, \quad \phi_{S}=\tan ^{-1}\left(\frac{\omega L_{i} I_{d}^{e^{*}}}{V_{g}-\omega L_{i} I_{q}^{e^{*}}}\right) .
$$

If the DC-link capacitor voltage is maintained at the constant operating point $\left(V_{d c}{ }^{*}\right)$, the power absorbed in the DC-link capacitor can be obtained as follows: 


$$
\begin{aligned}
p_{d c} & =\frac{C_{d c}}{2} \frac{d v_{d c}^{2}}{d t} \\
& =P_{S}\left\{\delta i_{g} \sin \left(\omega t+\phi_{S}\right)+\frac{I_{d}^{e^{*}}}{2} \cos \left(2 \omega t+\phi_{S}\right)-\frac{I_{q}^{e^{*}}}{2} \sin \left(2 \omega t+\phi_{S}\right)\right\}
\end{aligned}
$$

Equation (7) shows that the current measurement offset causes the DC-link capacitor voltage to oscillate at the utility voltage frequency in single-phase grid-connected inverters. This ripple deteriorates the overall system performance because it generates inverter output current reference with harmonics; thus, the real inverter output current also has harmonic components.

\section{B. Three-phase Grid-connected Inverters}

Fig. 3 presents the block diagram of the current control in consideration of the measurement offsets in three-phase grid-connected inverters. In Fig. $3,\left(\delta e_{d}^{s}, \delta e_{q}^{s}\right)$ and $\left(\delta i_{d}{ }^{s}, \delta i_{q}{ }^{s}\right)$ denote the stationary dq-axis measurement offsets of utility voltages and inverter output current, respectively, whereas $\left(e_{d_{-} m}^{s}, e_{q_{-} m}^{s}\right)$ and $\left(i_{d_{-} m}^{s}, i_{q_{-} m}^{s}\right)$ denote the stationary dq-axis measurement values of utility voltages and inverter output current, respectively. If the utility phase voltages are sinusoidal-balanced voltages, the stationary dq-axis voltages are expressed as Equation (8). The stationary dq-axis reference values of the inverter output phase current can be expressed as Equation (9) to control the active and reactive power at the utility side. Moreover, if the space vector pulse width modulation is ideal and the measurement offsets are constant, the stationary dq-axis output currents at the steady state in the current control system using a PIR regulator are expressed as Equation (10).

$$
\begin{gathered}
e_{d}^{s}=E \cos \omega t \\
e_{q}^{s}=E \sin \omega t \\
i_{d}^{s^{*}}=I_{d}^{e^{*}} \cos \omega t-I_{q}^{e^{*}} \sin \omega t \\
i_{q}^{s^{*}}=I_{d}^{e^{*}} \sin \omega t+I_{q}^{e^{*}} \cos \omega t \\
i_{d}^{s}=I_{d}^{e^{*}} \cos \omega t-I_{q}^{e^{*}} \sin \omega t-\delta i_{d}^{s} \\
i_{q}^{s}=I_{d}^{e^{*}} \sin \omega t+I_{q}^{e^{*}} \cos \omega t-\delta i_{q}^{s}
\end{gathered}
$$

Equation (10) shows that the current measurement offsets cause DC current components injected into the utility side in three-phase grid-connected inverters. At the steady state, using Equations (8) and (10) yields stationary dq-axis inverter output voltages as follows:

$$
\begin{aligned}
v_{d}^{s} & =L_{i} \frac{d i_{d}^{s}}{d t}+e_{d}^{s} \\
& =-\omega L_{i} I_{d}^{e^{*}} \sin \omega t-\omega L_{i} I_{q}^{e^{*}} \cos \omega t+E \cos \omega t \\
v_{q}^{s} & =L_{i} \frac{d i_{q}^{s}}{d t}+e_{q}^{s} \\
& =\omega L_{i} I_{d}^{e^{*}} \cos \omega t-\omega L_{i} I_{q}^{e^{*}} \sin \omega t+E \sin \omega t
\end{aligned}
$$

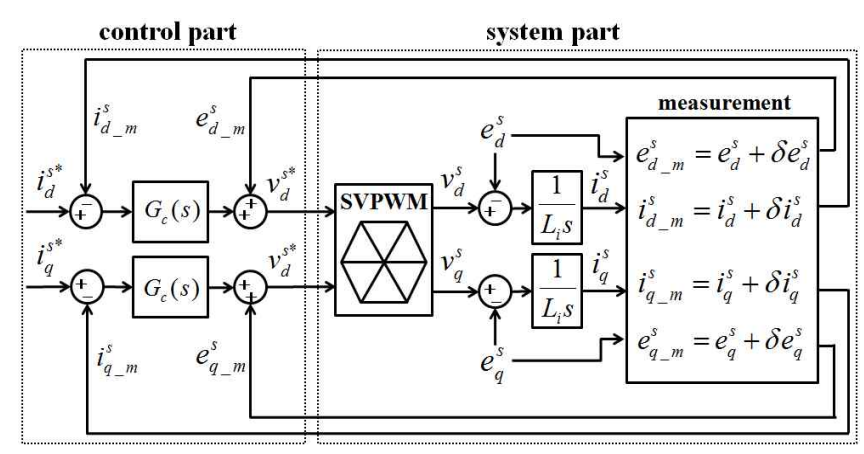

Fig. 3. Block diagram of the current control in consideration of the measurement offsets in three-phase grid-connected inverters.

If no power loss occurs in the inverter, the power supplied from the DC-link to the inverter is similar to the inverter output power and can be expressed as Equation (12).

$$
\begin{aligned}
& p_{\text {out }}=\frac{3}{2}\left(v_{d}^{s} i_{d}^{s}+v_{q}^{s} i_{q}^{s}\right)=p_{\text {out_dc }}+p_{\text {out__ } 1 r_{-} d}+p_{\text {out } \_1 r_{-} q} \\
& p_{\text {out_d }}=\frac{3}{2} E I_{d}^{e^{*}} \\
& p_{\text {out_1 } 1 r_{-} d}=-\frac{3}{2} P_{T}\left\{\delta i_{d}^{s} \cos \left(\omega t+\phi_{T}\right)\right\} \\
& p_{\text {out_1 } 1 r_{-} q}=-\frac{3}{2} P_{T}\left\{\delta i_{q}^{S} \sin \left(\omega t+\phi_{T}\right)\right\}
\end{aligned}
$$

where

$$
P_{T}=\sqrt{\left(E-\omega L_{i} I_{q}^{e^{*}}\right)^{2}+\left(\omega L_{i} I_{d}^{e^{*}}\right)^{2}}, \quad \phi_{T}=\tan ^{-1}\left(\frac{\omega L_{i} I_{d}^{e^{*}}}{E-\omega L_{i} I_{q}^{e^{*}}}\right) .
$$

If the DC-link capacitor voltage is maintained at the constant operating point $\left(V_{d c}{ }^{*}\right)$, the power absorbed in the DC-link capacitor can be obtained as follows:

$$
\begin{aligned}
p_{d c} & =\frac{C_{d c}}{2} \frac{d v_{d c}^{2}}{d t} \\
& =\frac{3}{2} P_{T}\left\{\delta i_{d}^{s} \cos \left(\omega t+\phi_{T}\right)+\delta i_{q}^{s} \sin \left(\omega t+\phi_{T}\right)\right\}
\end{aligned}
$$

Equation (13) shows that current measurement offsets cause the DC-link capacitor voltage to oscillate at the utility voltage frequency in three-phase grid-connected inverters. This ripple deteriorates the overall system performance because it generates inverter output current references with harmonics. Thus, real inverter output currents also have harmonic components.

\section{DESIGN OF THE CURRENT OFFSET COMPENSATOR}

\section{A. Single-phase Grid-connected Inverters}

From Equation (7), the equation for the ripple component of the DC-link capacitor voltage can be calculated as follows: 


$$
\begin{aligned}
v_{d c_{-} \text {rip }}^{2} & =v_{d c}^{2}-V_{d c}^{* 2}=\frac{2}{C_{d c}} \int p_{d c} d t \\
= & \frac{2 P_{S}}{\omega C_{d c}}\left\{-\delta i_{g} \cos \left(\omega t+\phi_{S}\right)\right\} \\
& +\frac{2 P_{S}}{\omega C_{d c}}\left\{\frac{I_{d}^{e^{*}}}{4} \sin \left(2 \omega t+\phi_{S}\right)+\frac{I_{q}^{e^{*}}}{4} \cos \left(2 \omega t+\phi_{S}\right)\right\}
\end{aligned}
$$

Equation (14) can be approximated as Equation (15) because the magnitude of the utility voltage is much larger than the impedance drop $\left(v_{g} \gg \omega L_{i} I_{d}{ }^{e^{*}}, \omega L_{i} I_{q}{ }^{e^{*}}\right)$.

$$
v_{d c_{-} \text {rip }}^{2} \cong \frac{2 V_{g}}{\omega C_{d c}}\left\{-\delta i_{g} \cos \omega t+\frac{I_{d}^{e^{*}}}{4} \sin 2 \omega t+\frac{I_{q}^{e^{*}}}{4} \cos 2 \omega t\right\}
$$

As shown in Equation (15), the second-order ripple component exists in single-phase grid-connected inverters. The band pass filter expressed in Equation (16) is used to detect the first-order ripple component included in the current measurement offset.

$$
T_{B P F}(s)=\frac{B W s}{s^{2}+B W s+\omega_{B P F}^{2}}
$$

where $B W$ and $\omega_{B P F}$ are the bandwidth and the center frequency of the band pass filter, respectively. If $\omega_{B P F}$ is similar to the utility frequency, the first-order ripple component can be obtained with

$$
x_{q}=-\frac{2 V_{g}}{\omega C_{d c}} \delta i_{g} \cos \omega t .
$$

The first-order ripple component expressed in Equation (17) is then filtered through the all-pass filter expressed in Equation (18). When $\omega_{A P F}$ is equal to the utility frequency, the all-pass filter generates a virtual component expressed as Equation (19), which leads the first-order ripple component by $90^{\circ}$.

$$
\begin{array}{r}
T_{A P F}(s)=\frac{s-\omega_{A P F}}{s+\omega_{A P F}} \\
x_{d}=\frac{2 V_{g}}{\omega C_{d c}} \delta i_{g} \sin \omega t
\end{array}
$$

By substituting Equations (17) and (19) into Equation (20), the magnitude of the first-order ripple component can be established as Equation (21).

$$
\begin{gathered}
m=\left[\begin{array}{cc}
\sin \omega t & -\cos \omega t
\end{array}\right]\left[\begin{array}{l}
x_{d} \\
x_{q}
\end{array}\right] \\
m=\frac{2 V_{g}}{\omega C_{d c}} \delta i_{g}
\end{gathered}
$$

The current measurement offset can be calculated with Equation (21), but the real value cannot be determined without exact parameter values. Moreover, the current measurement offset may be altered by external factors. Hence, a current offset controller is used to maintain the calculated first-order component at zero (Fig. 4).

Fig. 5 presents the block diagram of a current control system using the proposed current offset compensator in

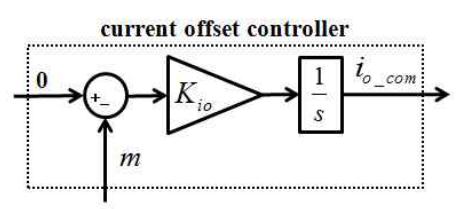

Fig. 4. Block diagram of a current offset controller in single-phase grid-connected inverters.

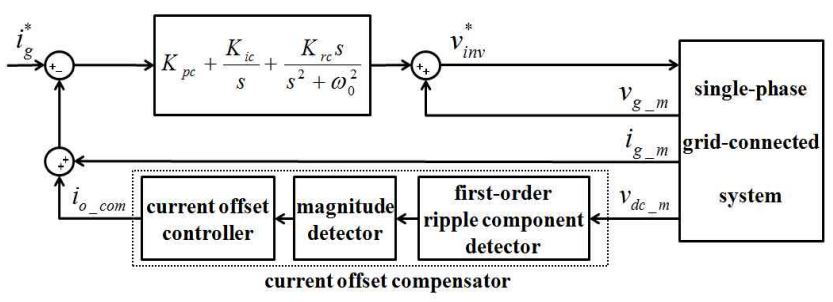

Fig. 5. Block diagram of a current control system using the proposed current offset compensator in single-phase grid-connected inverters.

single-phase grid-connected inverters. The current offset compensator is mainly composed of the first-order ripple component detector, the magnitude detector, and the current offset controller. In Fig. $5, i_{o_{-} \text {com }}$ is a compensation value for the current measurement offset.

\section{B. Three-phase grid-connected inverters}

From Equation (13), the equation for the ripple component of the DC-link capacitor voltage can be calculated as follows:

$$
\begin{aligned}
v_{d c_{-} \text {rip }}^{2} & =v_{d c}^{2}-V_{d c}^{* 2}=\frac{2}{C_{d c}} \int p_{d c} d t \\
& =\frac{3 P_{T}}{\omega C_{d c}}\left\{\delta i_{d}^{s} \sin \left(\omega t+\phi_{T}\right)-\delta i_{q}^{s} \cos \left(\omega t+\phi_{T}\right)\right\}
\end{aligned}
$$

Equation (22) can be approximated as Equation (23) because the magnitude of the utility voltage is much larger than the impedance drop $\left(E \gg \omega L_{i} I_{d}{ }^{e^{*}}, \omega L_{i} I_{q}{ }^{{ }^{*}}\right)$.

$$
x_{q} \cong \frac{3 E}{\omega C_{d c}}\left(\delta i_{d}^{s} \sin \omega t-\delta i_{q}^{s} \cos \omega t\right)
$$

Using the all-pass filter expressed in Equation (18), the virtual component that leads the first-order ripple component by $90^{\circ}$ can be obtained as follows:

$$
x_{d}=\frac{3 E}{\omega C_{d c}}\left(\delta i_{d}^{s} \cos \omega t+\delta i_{q}^{s} \sin \omega t\right) .
$$

The magnitude of the $\mathrm{d}$-axis and q-axis voltage ripple can be obtained with Equation (26) by substituting Equations (23) and (24) into Equation (25).

$$
\begin{aligned}
& {\left[\begin{array}{l}
m_{d} \\
m_{q}
\end{array}\right]=\left[\begin{array}{cc}
\cos \omega t & \sin \omega t \\
\sin \omega t & -\cos \omega t
\end{array}\right]\left[\begin{array}{l}
x_{d} \\
x_{q}
\end{array}\right]} \\
& {\left[\begin{array}{l}
m_{d} \\
m_{q}
\end{array}\right]=\left[\begin{array}{l}
\frac{3 E}{\omega C_{d c}} \delta i_{d}^{s} \\
\frac{3 E}{\omega C_{d c}} \delta i_{q}^{s}
\end{array}\right]}
\end{aligned}
$$




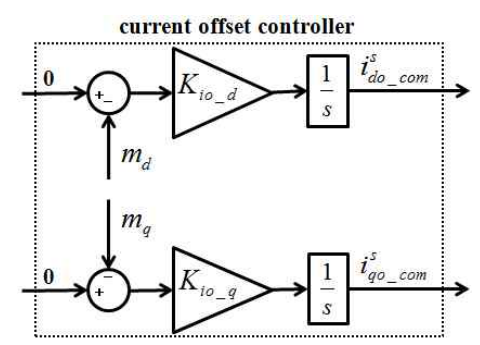

Fig. 6. Block diagram of a current offset controller in three-phase grid-connected inverters.

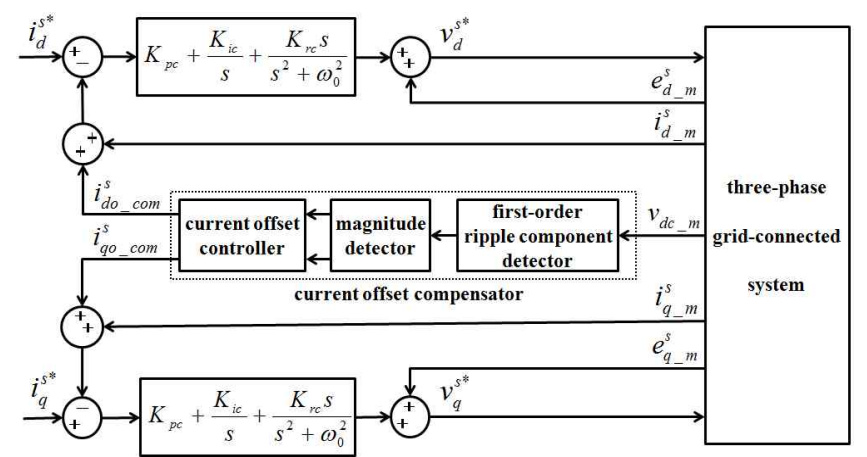

Fig. 7. Block diagram of a current control system using the proposed current offset compensator in three-phase grid-connected inverters.

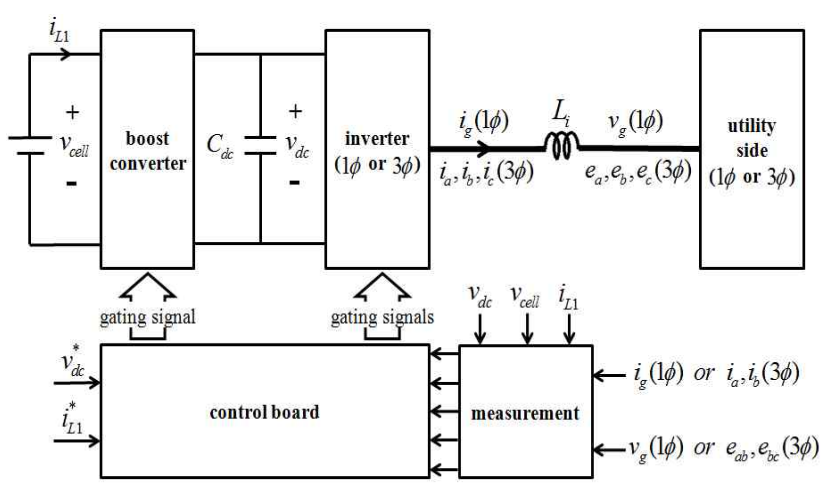

Fig. 8. Sample distributed generation system for simulations and experiments.

Similar to single-phase grid-connected inverters, using a current offset controller (Fig. 6) is necessary.

Fig. 7 presents the block diagram of a current control system using the proposed current offset compensator in three-phase grid-connected inverters. In Fig. 7, $i_{d o}{ }^{s}$ com and $i_{q o}{ }^{s}$ com are stationary dq-axis compensation values for current measurement offsets.

\section{Simulation Results}

Simulations and experiments were conducted with a sample distributed generation system (Fig. 8) to investigate
TABLE I

Parameters of The SAMPle Distributed Generation System

\begin{tabular}{|c|c|c|c|}
\hline \multirow{7}{*}{$\begin{array}{l}\text { Common } \\
\text { environment }\end{array}$} & \multicolumn{2}{|c|}{ Line-to-line voltage of utility } & $110 \mathrm{~V}$ \\
\hline & \multicolumn{2}{|l|}{ Frequency of utility } & $60 \mathrm{~Hz}$ \\
\hline & \multicolumn{2}{|c|}{ DC-link capacitor $\left(C_{d c}\right)$} & $1410 \mu \mathrm{F}$ \\
\hline & \multicolumn{2}{|c|}{ Interface inductor $\left(L_{i}\right)$} & $6 \mathrm{mH}$ \\
\hline & \multicolumn{2}{|c|}{ DC-link capacitor voltage reference $\left(v_{d c}{ }^{*}\right)$} & $210 \mathrm{~V}$ \\
\hline & \multicolumn{2}{|c|}{ Bandwidth of DC-link voltage controller } & $100 \mathrm{rad} / \mathrm{s}$ \\
\hline & \multicolumn{2}{|c|}{ Bandwidth of current controller } & $1000 \mathrm{rad} / \mathrm{s}$ \\
\hline Experiment & \multicolumn{2}{|l|}{ Switching frequency } & $10 \mathrm{kHz}$ \\
\hline \multirow{5}{*}{ Simulation } & \multicolumn{2}{|c|}{$\begin{array}{c}\text { Compensation start time of current } \\
\text { measurement offsets }\end{array}$} & $2 \mathrm{~s}$ \\
\hline & \multirow{2}{*}{$\begin{array}{c}\text { Measurement offsets } \\
\text { (single-phase grid-connected } \\
\text { inverters) }\end{array}$} & $\delta v_{g}$ & $3 \mathrm{~V}$ \\
\hline & & $\delta i_{g}$ & $-1 \mathrm{~A}$ \\
\hline & \multirow{2}{*}{$\begin{array}{c}\text { Measurement offsets } \\
\text { (three-phase grid-connected } \\
\text { inverters) }\end{array}$} & $\delta e_{d}^{s}, \delta e_{q}^{s}$ & $3 \mathrm{~V},-2 \mathrm{~V}$ \\
\hline & & $\delta i_{d}^{s}, \delta i_{q}^{s}$ & $1 \mathrm{~A},-1 \mathrm{~A}$ \\
\hline
\end{tabular}

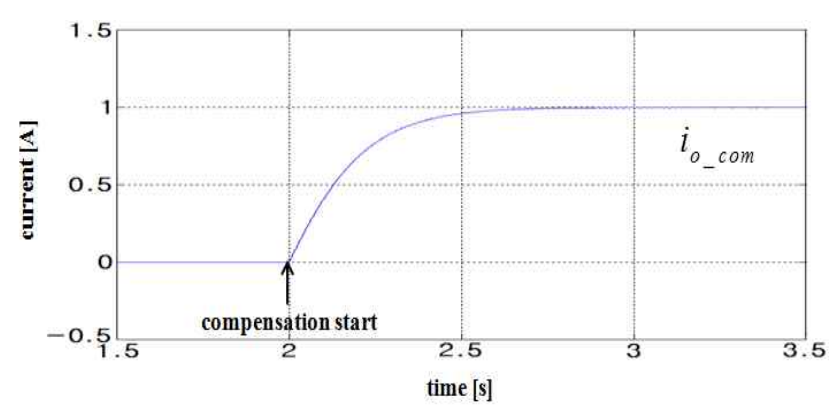

Fig. 9. Output of the current offset compensator in single-phase grid-connected inverters.

the effect of offsets in grid-connected inverters and to verify the performance of the proposed current offset compensator. In the sample distributed generation system, a new renewable energy source was modeled as a DC voltage source. The detailed parameters are listed in Table I. In the case of single-phase grid-connected inverters, a second-order voltage ripple that distorts the inverter output current inevitably exists in the DC-link capacitor voltage. A notch filter whose center frequency is twice the utility frequency was utilized to eliminate the effect of the ripple component.

Fig. 9 shows an output of the current offset compensator in single-phase grid-connected inverters. In the figure, the output of the current offset compensator converges at $1 \mathrm{~A}$ at the steady state to eliminate the effect of the current measurement offset. 
(a)

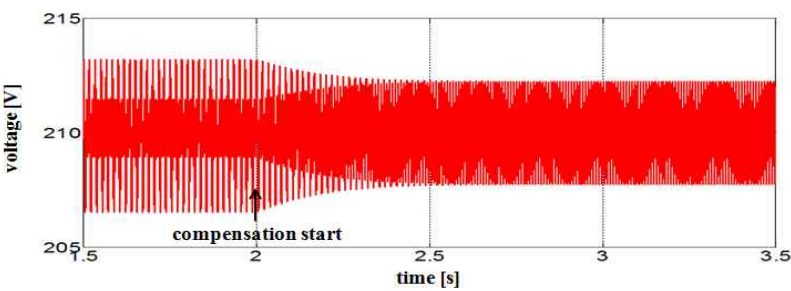

(b)

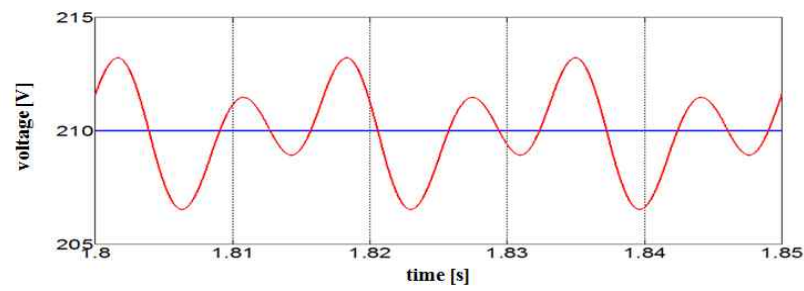

(c)

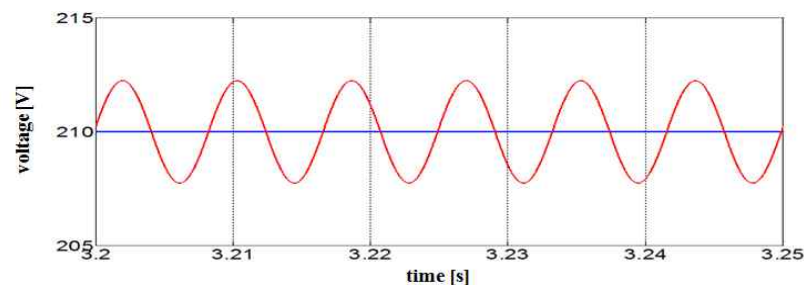

Fig. 10. DC-link capacitor voltage in single-phase grid-connected inverters (a) before and after compensation of current measurement offset. (b) Steady state characteristic before compensation. (c) Steady state characteristic after compensation.

Fig. 10 shows the DC-link capacitor voltage waveform in single-phase grid-connected inverters. Fig. 10(a) shows characteristics of transient and steady states before and after compensation. Figs. 10(b) and 10(c) show the magnified waveform of the DC-link capacitor voltage at the steady state before and after compensation, respectively. Comparison of Figs. 10(b) and 10(c) shows that the first-order ripple component disappeared after compensation, leaving only the second-order ripple component. This scenario is an inherent characteristic of single-phase grid-connected inverters. Fig. 10 shows that the DC component in the real inverter output current also disappeared.

Fig. 11 shows the fast Fourier transform (FFT) analysis of the inverter output current at the steady state before and after compensation. Fig. 11(a) shows the DC and second-order harmonic components before compensation. The second-order harmonic component is caused by the first-order ripple component of the DC-link capacitor voltage. After compensation by the proposed method, the DC component and the second-order harmonic of the inverter output current are almost eliminated as shown in Fig. 11(b).

Fig. 12 shows the output of the current offset compensator in three-phase grid-connected inverters. Similar to single-phase grid-connected inverters, the current offset compensator calculates the compensation values at the steady state. The effect of the current measurement offset is thus eliminated. (a)
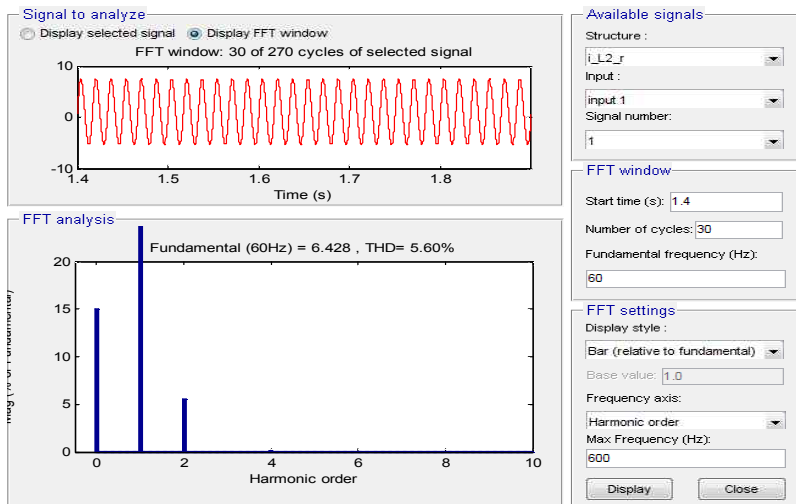

(b)
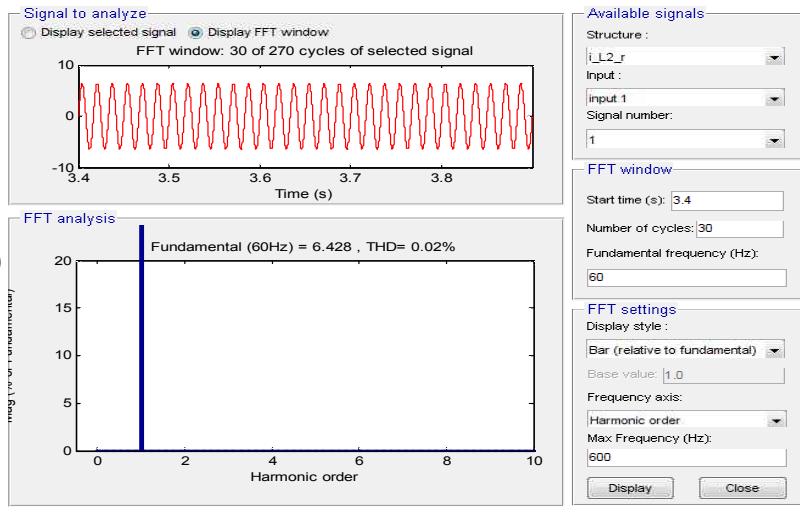

Fig. 11. FFT analysis result of inverter output current at the steady state in single-phase grid-connected inverters (a) before compensation and (b) after compensation.

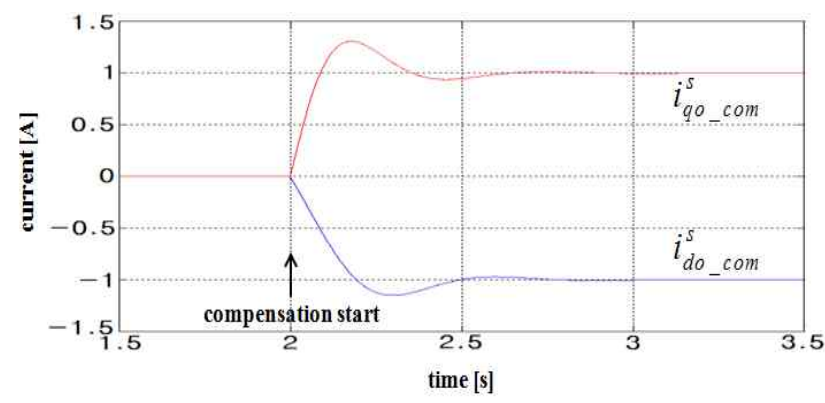

Fig. 12. Output of the current offset compensator in three-phase grid-connected inverters.

Fig. 13 shows the DC-link capacitor voltage waveform in three-phase grid-connected inverters. Fig. 13(a) shows the characteristics of transient and steady states before and after compensation. Figs. 13(b) and 13(c) show the magnified waveform of the DC-link capacitor voltage at the steady state before and after compensation, respectively. Comparison of Figs. 13(b) and 13(c) shows that the first-order ripple component disappeared after compensation. Fig. 13 shows that the DC component in the real inverter output currents also disappeared. 
(a)

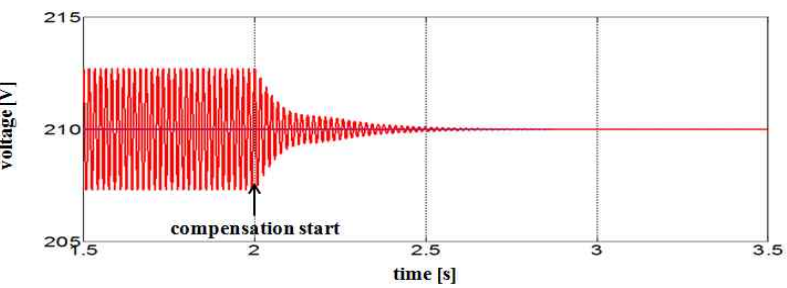

(b)

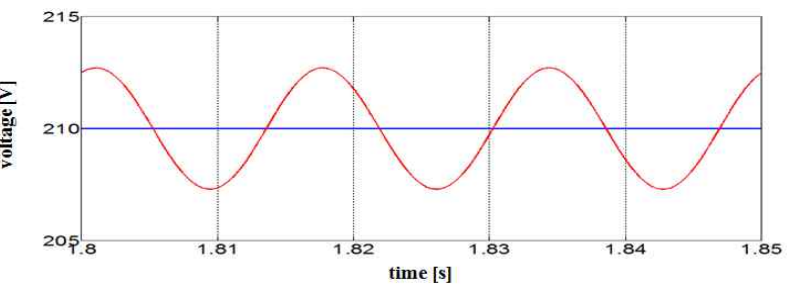

(c)

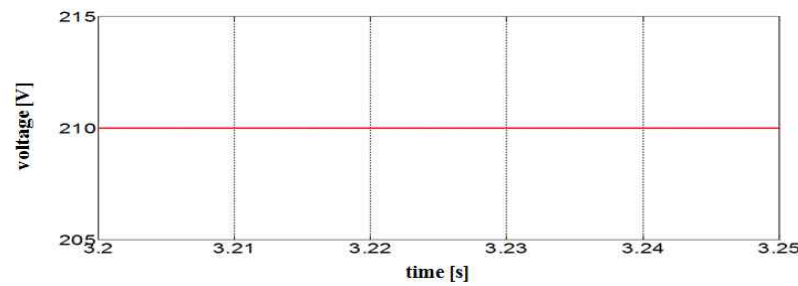

Fig. 13. DC-link capacitor voltage in three-phase grid-connected inverters (a) before and after compensation of current measurement offset. (b) Steady state characteristic before compensation. (c) Steady state characteristic after compensation.

(a)
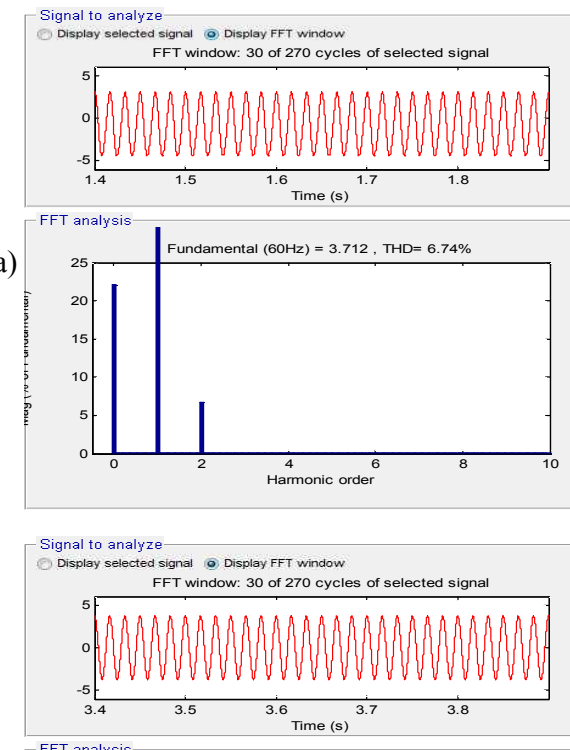

(b)
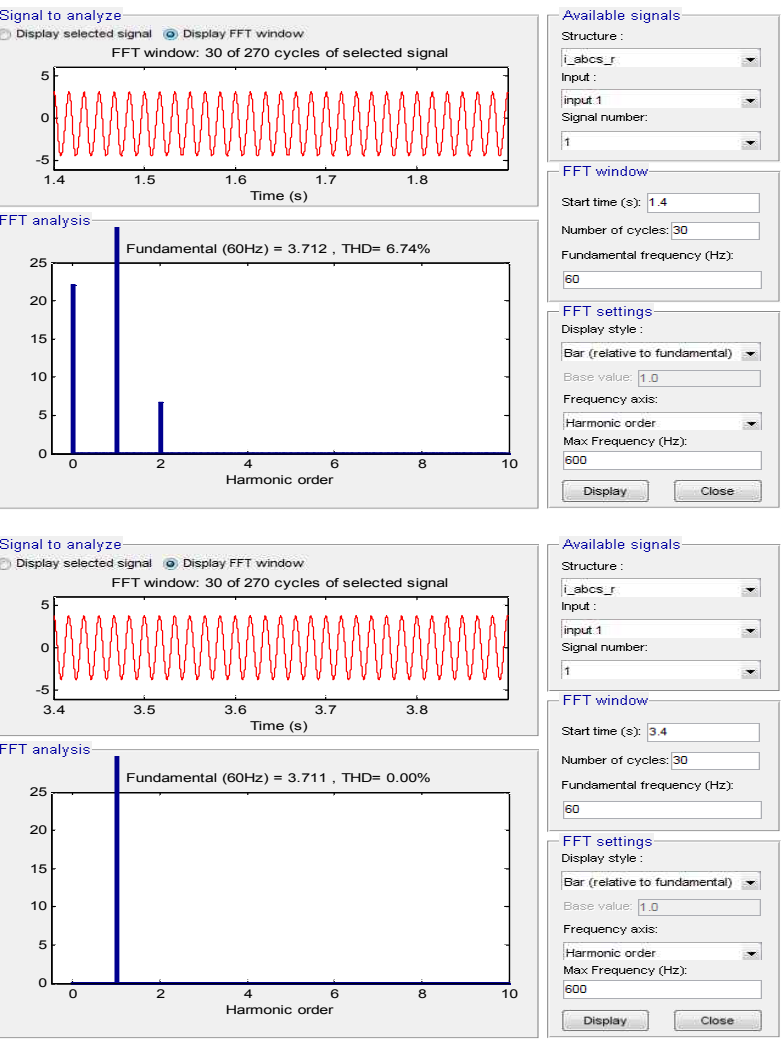

Fig. 14. FFT analysis result of inverter output current at the steady state in three-phase grid-connected inverters (a) before compensation and (b) after compensation.

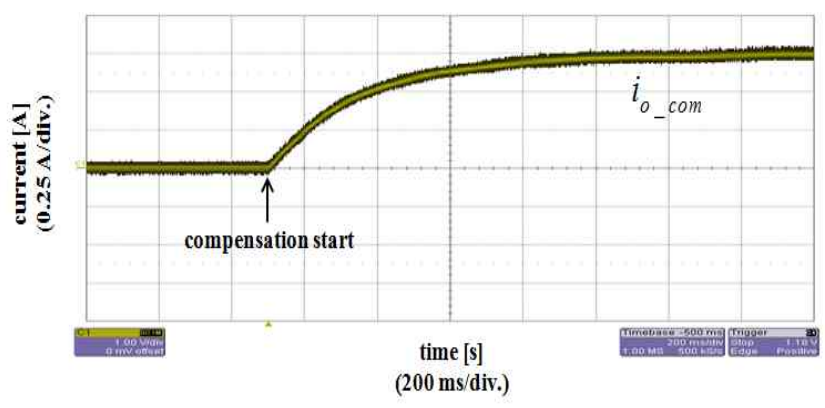

Fig. 15. Output of the current offset compensator in single-phase grid-connected inverters.

Fig. 14 shows the FFT analysis of the inverter output current at the steady state before and after compensation. Fig. 14(a) shows the DC and second-order harmonic components before compensation. The second-order harmonic component is caused by the first-order ripple component of the DC-link capacitor voltage. After compensation by the proposed method, the DC component and the second-order harmonic of the inverter output current are almost eliminated as shown in Fig. 14(b).

\section{EXPERIMENTAL RESULTS}

The configuration of the experimental system is shown in Fig. 8, and the parameters are listed in Table 1. TMS320F2812 was employed as a digital signal processor (DSP) in the experiment, and LA25-NP was utilized as a current sensor. The range of the current input was designed to be between $-15 \mathrm{~A}$ and $15 \mathrm{~A}$. The transduced current signals were converted to digital values by $12-$ bit $\mathrm{A} / \mathrm{D}$ converters, and all internal data in the DSP were displayed on an oscilloscope through a 12-bit D/A converter.

Fig. 15 shows the output of the current offset compensator in single-phase grid-connected inverters. The current measurement offset in the experiment is approximately -0.75 A. The result is similar to the simulation result in Fig. 9.

The ripple component of the DC-link capacitor voltage in single-phase grid-connected inverters before and after compensation is shown in Fig. 16. The figure also shows that the results similar to those of the simulation (Fig. 10).

An experiment for three-phase grid-connected inverters was also performed. The output of the current offset compensator is shown in Fig. 17. The current measurement offsets of the experimental systems are approximately $-0.3 \mathrm{~A}$ and $0.3 \mathrm{~A}$ in the stationary $\mathrm{d}$-axis and q-axis, respectively, similar to the simulation in Fig. 12.

Fig. 18 shows the ripple component of the DC-link capacitor voltage in three-phase grid-connected inverters. As shown in Fig. 18, the first-order ripple component present before compensation is almost eliminated after compensation. 
(a)

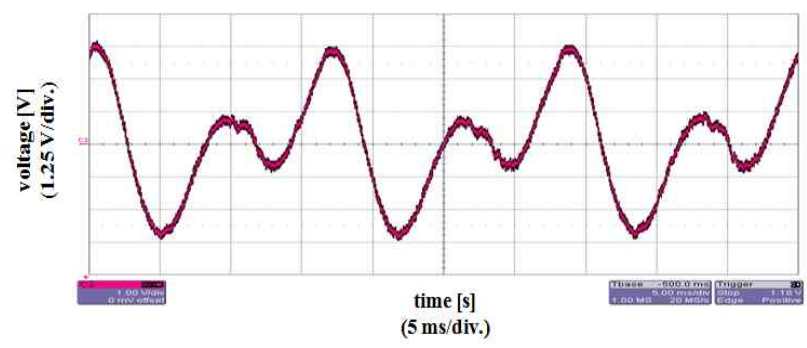

(b)

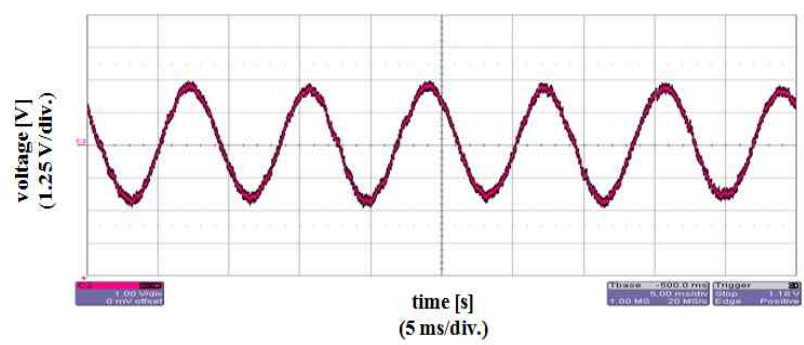

Fig. 16. Ripple component of DC-link capacitor voltage in single-phase grid-connected inverters (a) before compensation and (b) after compensation.

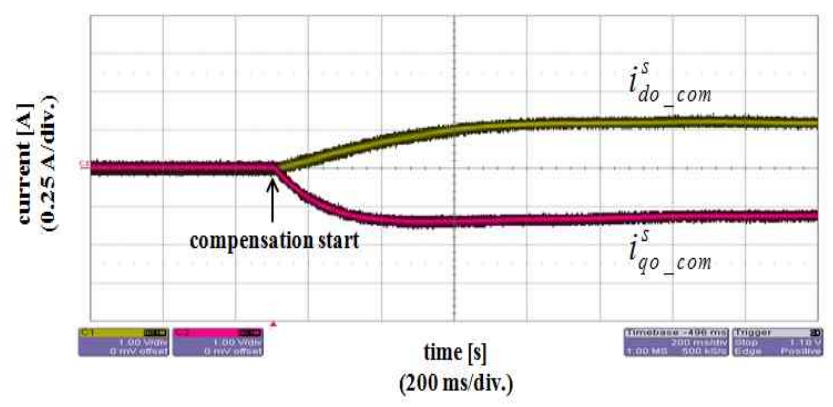

Fig. 17. Output of the current offset compensator in three-phase grid-connected inverters.

(a)

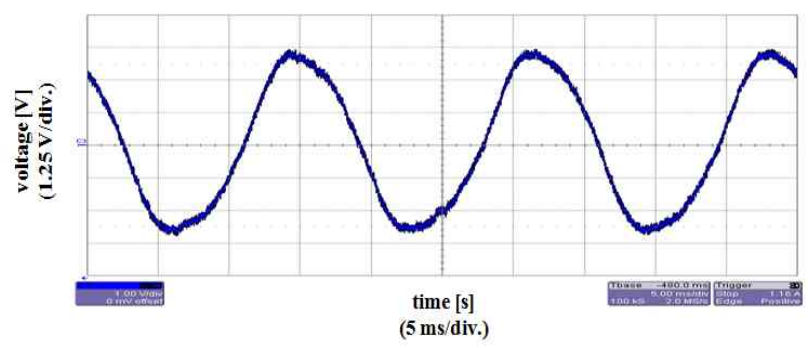

(b)

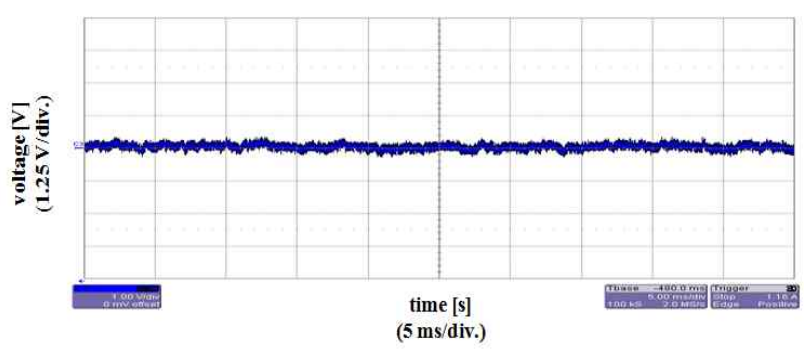

Fig. 18. Ripple component of the DC-link capacitor voltage in three-phase grid-connected inverters (a) before compensation and (b) after compensation.

\section{CONCLUSIONS}

In grid-connected inverters, current measurement offsets that are inevitably generated by the current measurement path cause DC current components in real inverter output currents. Real inverter output currents with DC components cause the DC-link capacitor voltage to oscillate at the frequency of the utility voltage. In this study, a compensation strategy to eliminate the effect of these current measurement offsets was proposed. The validity of the strategy was demonstrated through both simulations and experiments. The experimental results show that the DC components disappeared from inverter output currents after compensation. By changing the current regulator, the proposed compensation strategy can be applied to inverter output current references that include harmonics components, although only the fundamental component was considered in this study. If DC voltage components exist in real utility voltages, the proposed compensation strategy eliminates DC current components in real inverter output currents. The proposed compensation strategy can thus improve the overall system performance of grid-connected inverters.

\section{REFERENCES}

[1] J. M. Carrasco, L. G. Franquelo, J. T. Bialasiewicz, E. Galvan, R. C. P. Guisado, Mz. A. M. Prats, J. I. Leon, and N. Moreno-Alfonso, "Power-Electronic systems for the grid integration of renewable energy sources: A survey," IEEE Trans. Ind. Electron., Vol. 53, No. 4, pp. 1002-1016, Aug. 2006.

[2] B. D. Min, J. P. Lee, J. H. Kim, T. J. Kim, D. W. Yoo, K. R. Ryu, J. J. Kim, and E. H. Song, "A novel grid-connected PV PCS with new high efficiency converter," Journal of Power Electronics, Vol. 8, No. 4, pp. 309-316, Oct. 2008.

[3] J. K. Jeong, B. M. Han, J. Y. Lee, and N. S. Choi, "High-efficiency grid-tied power conditioning system for fuel cell power generation," Journal of Power Electronics, Vol. 11, No. 4, pp. 551-560, Jul. 2011.

[4] K. Kirubakaran, S. Jain, and R. K. Nema, "DSP-controlled power electronic interface for fuel-cell-based distributed generation," IEEE Trans. Power Electron., Vol. 26, No. 12, pp. 3853-3864, Dec. 2011.

[5] B. Singh, K. Al-Haddad, and A. Chandra, "A review of active filters for power quality improvement," IEEE Trans. Ind. Electron., Vol. 46, No. 5, pp. 960-971, Oct. 1999.

[6] Mohamed Adel, Sherif Zaid, and Osama Mahgoub, "Improved active power filter performance based on an indirect current control technique," Journal of Power Electronics, Vol. 11, No. 6, pp. 931-937, Nov. 2011.

[7] K. H. Kwan, P. L. So, and Y. C. Chu, "An output regulation-based unified power quality conditioner with Kalman filters," IEEE Trans. Ind. Electron., Vol. 59, No. 11, pp. 4248-4262, Nov. 2012.

[8] IEEE Standard for Interconnecting Distributed Resources with Electric Power Systems, IEEE Standard 1547-2003.

[9] D. G. Infield, P. Onions, A. D. Simmons, and G. A. Smith, "Power quality from multiple grid-connected single-phase inverters," IEEE Trans. Power Del., Vol. 19, No. 4, pp. 1983-1989, Oct. 2004. 
[10] L. Gertmar, P. Karlsson, and O. Samuelsson, "On DC injection to AC grids from distributed generation," in Proc. Eur. Conf. Power Electron. Appl., p. 10, 2005.

[11] M. P. Kazmierkowski and L. Malesani, "Current control techniques for three-phase voltage-source PWM converters: a survey," IEEE Trans. Ind. Electron., Vol. 45, No. 5, pp. 691-703, Oct. 1998.

[12] R. Y. Kim, S. Y. Choi, and I. Y. Suh, "Instantaneous control of average power for grid tie inverter using single phase D-Q rotating frame with all pass filter," in Proc. IEEE 30 th Annu. IEEE IECON, Vol. 1, pp. 274-279, 2004.

[13] D. N. Zmood, D. G. Holmes, and G. H. Bode, "Frequency-domain analysis of three-phase linear current regulators," IEEE Trans. Ind. Appl., Vol. 37, No. 2, pp. 601-610, Mar./Apr. 2001.

[14] D. N. Zmood and D. G. Holmes, "Stationary frame current regulation of PWM inverters with zero steady-state error," IEEE Trans. Power Electron., Vol. 18, No. 3, pp. 814-822, May 2003.

[15] R. Teodorescu, F. Blaabjerg, M. Liserre, and P. C. Loh, "Proportional-resonant controllers and filters for grid-connected voltage-source converters," IEE Proc.-Electr. Power Appl., Vol. 153, No. 5, pp. 750-762, Sep. 2006.

[16] S. Jiang, D. Cao, Y. Li, and F. Z. Peng, "Grid-connected boost-half-bridge photovoltaic microinverter system using repetitive current control and maximum power point tracking," IEEE Trans. Power Electron., Vol. 27, No. 11, pp. 4711-4722, Nov. 2012.

[17] L. Hang, S. Liu, G. Yan, B. Qu, and Z. Lu, "An improved deadbeat scheme with fuzzy controller for the grid-side three-phase PWM boost rectifier," IEEE Trans. Power Electron., Vol. 26, No. 4, pp. 1184-1191, Apr. 2011.

[18] J. A. Suul, K. Ljokelsoy, T. Midtsund, and T. Undeland, "Synchronous reference frame hysteresis current control for grid converter applications," IEEE Trans. Ind. Appl., Vol. 47, No. 5, pp. 2183-2194, Sep./Oct. 2011.
[19] A. K. S. Bhat and S. B. Dewan, "A novel utility interfaced high-frequency link photovoltaic power conditioning system," IEEE Trans. Ind. Electron., Vol. 35, No. 1, pp. 153-159, Feb. 1988.

[20] W. M. Blewitt, D. J. Atkinson, J. Kelly, and R. A. Lakin, "Approach to low-cost prevention of DC injection in transformerless grid connected inverters," IET Power Electron., Vol. 3, No. 1, pp. 111-119, Jan. 2010.

[21] L. Bowtell and A. Ahfock, "Direct current offset controller for transformerless single-phase photovoltaic grid-connected inverters," IET Renew. Power Gen., Vol. 4, No. 5, pp. 428-437, Sep. 2010.

[22] G. Buticchi, E. Lorenzani, and G. Franceschini, "A DC offset current compensation strategy in transformerless grid-connected power converters," IEEE Trans. Power Del., Vol. 26, No. 4, pp. 2743-2751, Oct. 2011.

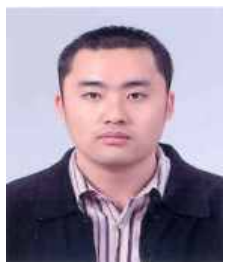

Chang-Hee Lee received his B.S. and M.S. degrees in electrical engineering from Kyungpook National University, Daegu, Korea, in 2008 and 2012, respectively. His current research interests include power-electronic control of electric machines, systems that use renewable energy sources, and custom power devices.

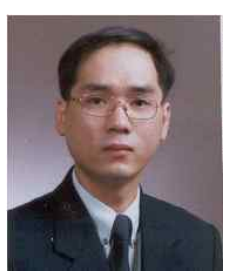

Jong-Woo Choi received his B.S., M.S., and $\mathrm{Ph} . \mathrm{D}$. degrees in electrical engineering from Seoul National University, Seoul, Korea, in 1991, 1993, and 1996, respectively. He worked as a research engineer at LG Industrial Systems Company from 1996 to 2000. Since 2001, he has been a faculty member of the Department of Electrical Engineering, Kyungpook National University, Daegu, Korea, where he is currently a professor. His current research interests include static power conversion and electric machine drives. 